\title{
Random regression models using different functions to model test-day milk yield of Brazilian Holstein cows
}

\author{
A.B. Bignardi', L. El Faro', R.A.A. Torres Júnior ${ }^{3}$, V.L. Cardoso', \\ P.F. Machado ${ }^{4}$ and L.G. Albuquerque ${ }^{1,5}$ \\ ${ }^{1}$ Departamento de Zootecnia, Faculdade de Ciências Agrárias e Veterinárias, \\ Universidade Estadual Paulista “Julio de Mesquita Filho", Jaboticabal, SP, Brasil \\ ${ }^{2}$ Agência Paulista de Tecnologia dos Agronegócios, Pólo Regional Centro Leste, \\ Ribeirão Preto, SP, Brasil \\ ${ }^{3}$ Embrapa Gado de Corte, Campo Grande, MS, Brasil \\ ${ }^{4}$ Departamento de Zootecnia, Escola Superior de Agricultura "Luiz de Queiroz", \\ Universidade de São Paulo, Piracicaba, SP, Brasil \\ ${ }^{5}$ Conselho Nacional de Desenvolvimento Científico e Tecnologico, \\ Instituto Nacional de Ciência e Tecnologia - Ciência Animal \\ Corresponding author: A.B. Bignardi \\ E-mail: annaizabb@hotmail.com
}

Genet. Mol. Res. 10 (4): 3565-3575 (2011)

Received March 18, 2011

Accepted September 10, 2011

Published October 31, 2011

DOI http://dx.doi.org/10.4238/2011.October.31.4

\begin{abstract}
We analyzed 152,145 test-day records from 7317 first lactations of Holstein cows recorded from 1995 to 2003. Our objective was to model variations in test-day milk yield during the first lactation of Holstein cows by random regression model (RRM), using various functions in order to obtain adequate and parsimonious models for the estimation of genetic parameters. Test-day milk yields were grouped into weekly classes of days in milk, ranging from 1 to 44 weeks. The contemporary groups were defined as herd-test-day. The analyses were performed using a single-trait RRM, including the direct additive, permanent environmental and residual random effects. In addition,
\end{abstract}


contemporary group and linear and quadratic effects of the age of cow at calving were included as fixed effects. The mean trend of milk yield was modeled with a fourth-order orthogonal Legendre polynomial. The additive genetic and permanent environmental covariance functions were estimated by random regression on two parametric functions, Ali and Schaeffer and Wilmink, and on B-spline functions of days in milk. The covariance components and the genetic parameters were estimated by the restricted maximum likelihood method. Results from RRM parametric and B-spline functions were compared to RRM on Legendre polynomials and with a multi-trait analysis, using the same data set. Heritability estimates presented similar trends during mid-lactation (13 to 31 weeks) and between week 37 and the end of lactation, for all RRM. Heritabilities obtained by multi-trait analysis were of a lower magnitude than those estimated by RRM. The RRMs with a higher number of parameters were more useful to describe the genetic variation of test-day milk yield throughout the lactation. RRM using B-spline and Legendre polynomials as base functions appears to be the most adequate to describe the covariance structure of the data.

Key words: Covariance functions; Parametric functions; Test-day; Segmented polynomials

\section{INTRODUCTION}

Random regression models (RRM) are commonly used for genetic evaluations of production traits in dairy cattle. In contrast to multi-trait models that only permit point predictions, these models predict breeding values for cumulative milk yield throughout lactation, milk yield at any specific day of lactation, and functions of the lactation curve. In addition, RRM permit the use of incomplete lactations and the consequent inclusion of a larger number of data from the same animal in genetic evaluations.

Different models can be proposed to evaluate test-day milk yield traits by random regression models according to Jensen (2001). Nevertheless, no consensus exists regarding the best model to fit milk yield data. The genetic parameter estimates obtained with RRM generally depend on the regression functions used and on the covariance structure for additive genetic, permanent environmental and residual effects. The first studies using RRM, in which residual effect were modeled considering a structure with homogeneous variances, identified problems in the partition of the remaining variance components, such as overestimation of additive genetic variances (Jamrozik and Schaeffer, 1997; Jamrozik et al., 1997). Therefore, a residual effect has been considered to be heterogeneous and has been modeled by grouping them into classes containing similar variations or by variance functions using orthogonal or ordinary polynomials (Olori et al., 1999; Brotherstone et al., 2000; El Faro and Albuquerque, 2003).

Random regression based on orthogonal Legendre polynomials has been used in most studies to model the structure of covariances for random additive genetic and permanent environmental effects (Strabel and Misztal, 1999; Olori et al., 1999; Araújo et al., 2006). Parametric functions such as the logarithmic polynomial proposed by Ali and Schaeffer (1987) and 
the Wilmink (1987) exponential function have also been used, with these functions providing genetic parameter estimates that differ from those obtained with orthogonal Legendre polynomials. Brotherstone et al. (2000), comparing RRM using orthogonal Legendre polynomials, the Ali and Schaeffer (1987) function and two variations of the Wilmink (1987) function to model random effects, concluded that the function used exerts a marked influence on the genetic parameter estimates and that the parametric functions of Ali and Schaeffer (1987) and Wilmink (1987) best fitted the data, despite negative correlations between test-days at the beginning and at the end of lactation. On the other hand, Araújo et al. (2006), who compared RRM using orthogonal Legendre polynomials and the parametric functions of Ali and Schaeffer (1987) and Wilmink (1987) to model random effects, concluded that orthogonal Legendre polynomials provided the best data fit.

According to Meyer (2005), RRM using polynomials of cubic, quartic or even higher orders provide erratic and implausible estimates of variance components and genetic parameters. This is especially observed for data sets that contain few records for the last ages and/ or few records per animal and in analyses in which the animals have fewer records than the order of the polynomials.

Alternatives to reduce the degree of polynomials have been studied, for example, spline functions, also called segmented polynomials. These functions are curves consisting of individual segments of low degree polynomials that merge into specific points, called knots. Spline functions can be modeled in different ways (different bases) and, depending on the choice, reduce multicollinearity, are easy to estimate (linear in the parameters), and possess a simple biological interpretation. In addition, spline functions generally permit both a good local and a good overall fit (Fuller, 1969; Schenkel, 1989). According to Ruppert et al. (2003) one particular type of spline functions is called B-splines, which are preferred because of their excellent numerical properties. Moreover B-splines are adequate to model random effects in mixed model analyses and are also effective in estimating covariance functions (Rice and $\mathrm{Wu}, 2001$ ).

The objective of the present study was to model variations in test-day milk yield during first lactation of Holstein cows by random regression analysis using different functions in order to obtain adequate and parsimonious models for the estimation of genetic parameters.

\section{MATERIAL AND METHODS}

A total of 152,145 test-day (TD) records from 7,317 first lactations of Holstein cows recorded from 1995 to 2003 were analyzed. The cows were descendants of 612 sires, were distributed over 93 herds located in the southeastern region of Brazil, with age at first calving ranging from 18 to 48 months. The data were obtained from the Herd Analyses and Milk Quality Program carried out by Clínica do Leite (Milk Quality Laboratory of Luiz de Queiroz Agriculture College, ESALQ-USP). Test-day milk yields were recorded from 305 days of lactation, with the first record being obtained up to 45 days after calving.

TD milk yields were divided and grouped into weekly classes of days in milk, ranging from 1 to 44 classes. Lactations with at least five individual records were included. The contemporary groups were defined as herd-test-day, with a total of 2,539 groups, and contained at least six animals per class. The relationship matrix included a total of 17,688 animals.

The analyzes were performed using a single-trait RRM, including the direct additive, permanent environmental and residual random effects. In addition, contemporary group and 
linear and quadratic effects of the age of cow at calving were included as fixed effects. The mean trend of milk yield was modeled with a fourth-order orthogonal Legendre polynomial. The additive genetic and permanent environmental covariance functions were estimated by random regression on two parametric functions Ali and Schaeffer (1987) and Wilmink (1987) and on B-spline functions of days in milk.

For models using parametric functions, step functions fitted, initially, by 44 classes of residual variances. Then, the pattern of variation was analyzed to define step functions with 6 and 17 residual variance. The classes were defined based on residual variances estimated using 44 classes. In this case, the weeks of lactation were grouped as follows: 1, 2, 3, 4-6, 7-12 and 13-44 weeks for the model with 6 classes; and 1, 2, 3, 4, 5, 6, 7, 8, 9, 10, 11-12, 13-24, 25-28, 29-39, 40, 41-42, 43 and 44 weeks for the model with 17 classes. Models with homogeneous residual variances were also tried. For B-spline model, residual variances were modeled by a step function with 6 classes of variance.

In matrix notation the model can be represented as

$$
\mathrm{y}=\mathrm{Xb}+\mathrm{Za}+\mathrm{Wpe}+\mathrm{e}
$$

where $y=$ the vector of observations measured in Nd animals; $b=$ the vector of fixed effects; $a$ $=$ the vector of additive genetic random coefficients; $p e=$ the vector of animal permanent environmental random coefficients; $e=$ the vector of the $\mathrm{N}$ different residuals; $X, Z, W=$ are the correspondent incidence matrices for fixed and additive genetic and permanent environmental random effects, respectively.

The Ali and Schaeffer (1987) function is represented by:

$$
y=a+b V+c V^{2}+d Z+e Z^{2} \text { where, } V=(t / 305) Z=\ln (305 / t)
$$

where $a$ is associated with peak yield, $b$ and $c$ are associated with the decreasing slope, $d$ and $e$, are associated with the increasing slope, and $t$ denotes day in milking.

The Wilmink (1987) function is represented by:

$$
y=a+b t+c \exp ^{(-0,05 t)}
$$

where $a, b$, and $c=$ parameters of the function, with $a$ being associated with the initial milk yield, $b$ with the decline in milk yield after peak lactation, $c$ with the increase in milk yield after peak lactation, and $t$ denotes day in milking. The B-spline functions were used to fit trends, using segmented functions as described by Meyer (2005). Each individual segment was considered linear $(\mathrm{L})$, with basis functions of degree $p=1$. Polynomials of the different orders were included in the model for direct additive, permanent environmental random effects. Up to seven knots equally spaced for direct additive genetic and animal permanent environment effects were considered. According to Meyer (2005), in random regression models using Bspline functions as basis function, a type of penalized spline, the choice of knot position is less crucial. $M$ knots were chosen to divide the age at recording into $m-1$ equally spaced intervals and the external knots are located in classes 1 and 44 for all models. The number of random regression coefficients to model the trajectory of the linear, basis functions is given by $m$.

The covariance components and the genetic parameters were estimated by restricted maximum likelihood method (REML), using the package Wombat (Meyer, 2006). 
Results from RRM parametric and B-splines functions were compared to RRM on Legendre polynomials and with a multi-trait analysis (MT) using the same data set. The models of multitrait analysis of monthly, considering each record as a different trait, included fixed effects of the contemporary groups (herd-year-month-test-day), age of cow (linear and quadratic effects), and days in milk (linear effect). The RRM on Legendre polynomials included sixth- and seventh-order orthogonal Legendre polynomials for direct additive genetic and permanent environmental effects of the animal, respectively, with the structure of residual variances being modeled by a step function with 6 variance classes. The model included the same fixed effects considered in parametric and B-splines functions. For more details, this applied model was reported by Bignardi et al. (2009a).

The RRM were compared using Akaike's (AIC) and Schwarz's Bayesian (BIC) information criteria (Wolfinger, 1993), as well as by the inspection of the variance and correlation estimates between milk yields on different test-days. The AIC and BIC allow the comparison between non-hierarchical models and penalize those models that contain a larger number of parameters, with the BIC attributing a more rigorous penalty.

The information criteria can be described as

$$
\begin{aligned}
& \mathrm{AIC}=-2 \log \mathrm{L}+2 \mathrm{p} \\
& \mathrm{BIC}=-2 \log \mathrm{L}+\mathrm{plog}(\mathrm{N}-\mathrm{r}),
\end{aligned}
$$

where $p$ is the number of parameters in the model, $N$ is the total number of observations, $r$ is the rank of the incidence matrix of fixed effects in the model, and $\log L$ is the logarithm of the restricted maximum likelihood function. Lower AIC and BIC indicate better fit. In addition, the variance components and genetic parameters estimated for each random regression model were also used as criteria to choose the most adequate model to describe the covariance structure of the data.

The RRM are referred to as X.k $\mathrm{k}_{\mathrm{a}} \cdot \mathrm{k}_{\mathrm{pe}}$.hetn or X.k. $\mathrm{k}_{\mathrm{a}} \cdot \mathrm{k}_{\mathrm{pe}} \cdot \mathrm{hom}$, with $\mathrm{X}$ corresponding to Wilmink (W), Ali and Schaeffer (AS), Legendre polynomials (LEG) or B-splines (BSL) functions, $\mathrm{k}_{\mathrm{a}}$ and $\mathrm{k}_{\mathrm{pe}}$ corresponding to the order for additive genetic and permanent environmental covariance functions, respectively, and to the residual structure of variances modeled by a step function (het) assuming $\mathrm{n}$ variance classes or variance homogeneity (hom).

\section{RESULTS AND DISCUSSION}

Mean test-day milk yield was $27.45 \mathrm{~kg}$, with a standard deviation of $7.61 \mathrm{~kg}$ and a coefficient of variation of $27.73 \%$. Test-day milk production showed the typical shape of the lactation curve of cows of European dairy breeds, starting at $18.19 \mathrm{~kg}$ on the first test-day, increasing to $29.55 \mathrm{~kg}$ on 17th week and decreasing gradually on subsequent test-days until reaching $23.63 \mathrm{~kg}$ on 44th week (Figure 1). The disgarding of contemporary groups with less than six animals explains the small number of animals at the 27th and 28th week.

The logarithm of the likelihood function ( $\log \mathrm{L})$, Akaike's information criterion (AIC) and Schwarz's Bayesian information criterion (BIC) are shown in Table 1. The number of parameters ranged from 13 to 74 in the models studied. According to the AIC and BIC, the models containing homogeneous residual variances provided the worst fit, irrespective of the parametric function used to model random effects. This finding indicates the need for a heterogeneous variance structure for residual effects since the variances tended to differ during lactation. For both parametric functions, the BIC values showed that model including six 


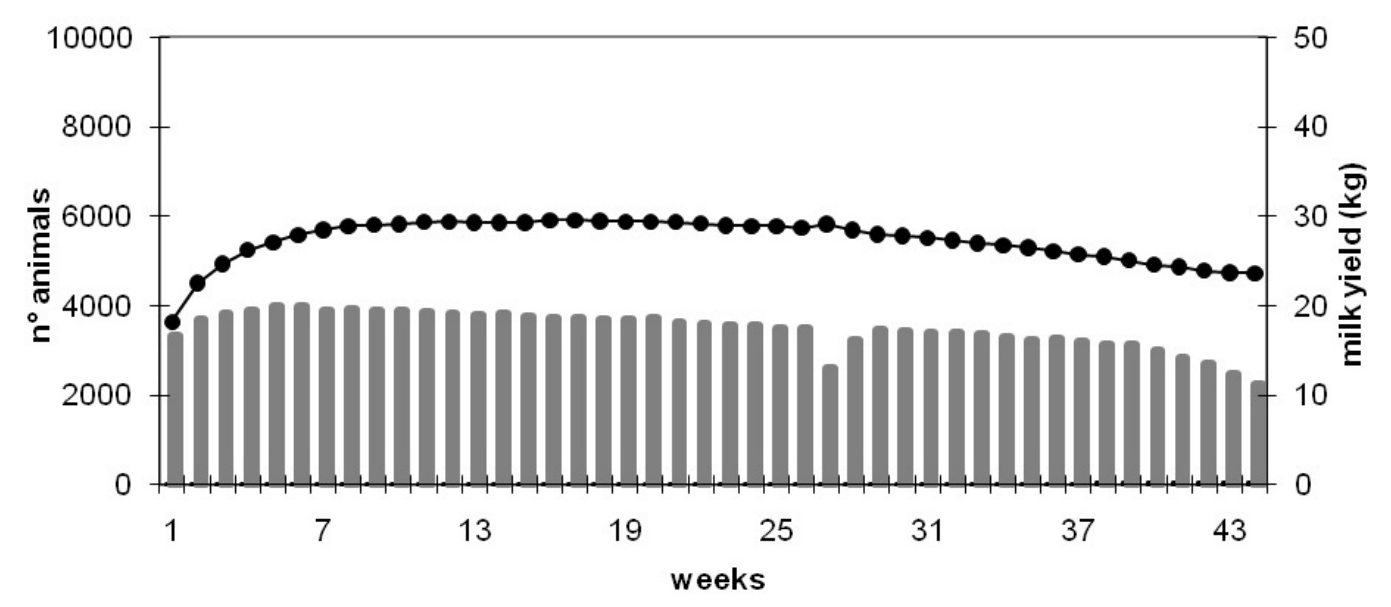

Figure 1. Number of animals and milk yield.

Table 1. Models, number of parameters (p) for different analyses together with the maximum log-likelihood ( $\log$ L), Akaike's information criterion (AIC) and Schwarz's Bayesian information criterion (BIC).

\begin{tabular}{|c|c|c|c|c|}
\hline Models* & $\mathrm{p}$ & $\log \mathrm{L}$ & AIC & $\mathrm{BIC}$ \\
\hline \multicolumn{5}{|l|}{ Wilmink } \\
\hline W.3.3.hom & 13 & -299242 & 598510 & 598639 \\
\hline W.3.3.het6 & 18 & -295664 & 591363 & 591542 \\
\hline W.3.3.het17 & 29 & -295664 & 591385 & 591673 \\
\hline W.3.3.het44 & 56 & -295620 & 591351 & 591908 \\
\hline \multicolumn{5}{|l|}{ Ali \& Schaeffer } \\
\hline AS.5.5.hom & 31 & -290581 & 581225 & 581532 \\
\hline AS.5.5.het6 & 36 & -290353 & 580777 & 581136 \\
\hline AS.5.5.het17 & 47 & -290353 & 580799 & 581266 \\
\hline AS.5.5.het44 & 74 & -290326 & 580800 & 581335 \\
\hline \multicolumn{5}{|l|}{ B-spline } \\
\hline BSL.4.4.het6 & 26 & -291767 & 583586 & 583844 \\
\hline BSL.4.5.het6 & 31 & -291043 & 582086 & 582392 \\
\hline BSL.4.6.het6 & 37 & -290369 & 580812 & 581178 \\
\hline BSL.4.7.het6 & 44 & -290126 & 580340 & 580776 \\
\hline BSL.5.4.het6 & 31 & -291069 & 582200 & 582506 \\
\hline BSL.5.5.het6 & 36 & -290928 & 581928 & 582286 \\
\hline BSL.5.6.het6 & 42 & -290310 & 580704 & 581120 \\
\hline BSL.5.7.het6 & 49 & -290058 & 580214 & 580700 \\
\hline BSL.6.5.het6 & 42 & -290360 & 580804 & 581220 \\
\hline BSL.6.6.het6 & 48 & -290224 & 580544 & 581020 \\
\hline BSL.6.7.het6 & 55 & -290006 & 580122 & 580666 \\
\hline BSL.7.6.het6 & 55 & -290050 & 580210 & 580754 \\
\hline BSL.7.7.het6 & 62 & -289921 & 579966 & 580580 \\
\hline \multicolumn{5}{|l|}{ Legendre polynomials } \\
\hline LEG.6.7.het6 & 55 & -289847 & 579804 & 580350 \\
\hline
\end{tabular}

*Models: X.ka.kpe.hetn or X.ka.kpe.hom, X corresponding the functions Wilmink (W), Ali and Schaeffer (AS), Legendre polynomials (LEG) or B-splines (BSL), ka corresponding to the order of the covariance function for additive genetic and permanent environmental (kpe) effects and to the residual structure of variances modeled by a step function (het) assuming $\mathrm{n}$ variance classes or variance homogeneity (hom).

heterogeneous classes of residual variances, was the best model. According to AIC and BIC, the Ali and Schaeffer function was better than the Wilmink function. Similar results have been reported by Brotherstone et al. (2000), Melo et al. (2007), and Costa et al. (2008). 
Comparison of the RRM using only B-splines showed that AIC and BIC decreased when the same number of coefficients was used for additive genetic effect and the number of coefficients for permanent environmental effects was increased. None of the random regressions on parametric or B-spline functions employing a similar or smaller number of parameters presented a better fit than the Legendre polynomial (LEG.6.7.het6). A larger number of parameters were necessary so that the RRM using B-spline functions would provide AIC and BIC values similar to those observed for model LEG.6.7.het6. Model BSL.7.7.het6 presented close $\log$ L, AIC and BIC values when compared to model LEG.6.7.het6. RRM fitting Bsplines functions as basis functions tended to involve more coefficients than corresponding analyses with polynomial basis functions (Meyer, 2005).

The phenotypic, genetic, permanent environmental and residual variances obtained with models W.3.3het6, AS.5.5.het6, LEG.6.7.het6 and BSL.7.7.het6 and the multi-trait model are shown in Figure 2. The phenotypic variances estimated with these four RRM were closely similar, except for the first 3 weeks, and showed the same trend throughout lactation. Comparing the phenotypic variances obtained with the RRM and by multi-trait analysis, a difference was only observed for the estimate of the last monthly test-day. This finding might be explained by the smaller number of records available as a consequence of the proximity to the dry period and to the period of gestation.
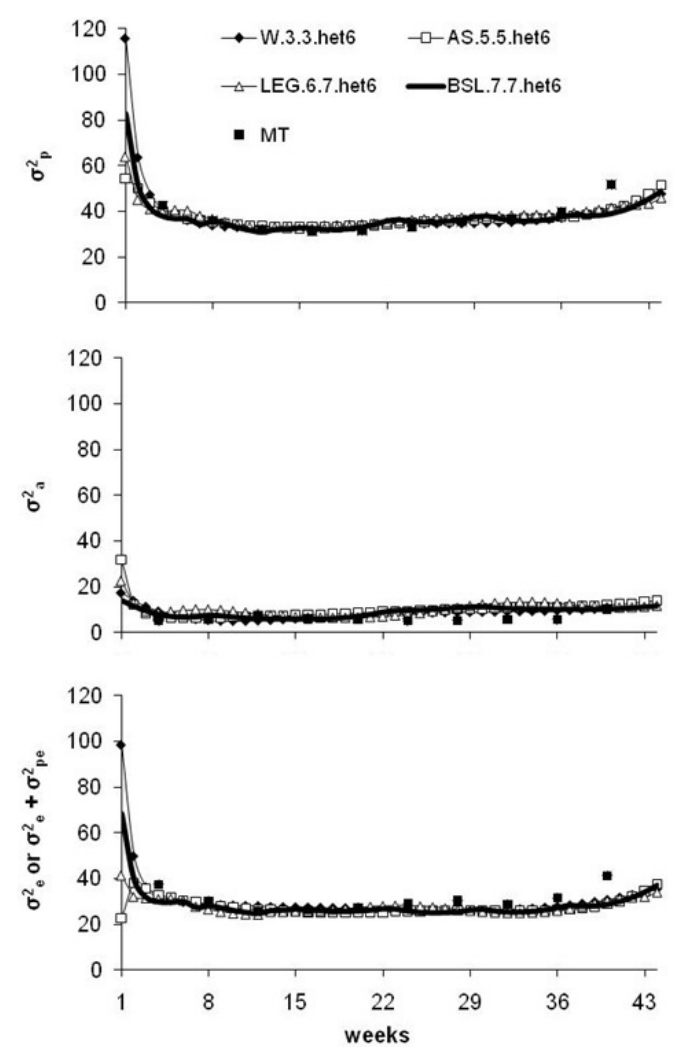

Figure 2. Phenotypic $\left(\sigma_{\mathrm{p}}^{2}\right)$, genetic $\left(\sigma_{\mathrm{a}}^{2}\right)$ and residual variances $\left(\sigma_{\mathrm{pe}+}^{2} \sigma_{\mathrm{e}}^{2}\right.$ ou $\left.\sigma_{\mathrm{e}}^{2}\right)$ estimated by W.3.3het6, AS.5.5.het6, LEG.6.7.het6, BSL.7.7.het6 the random regression models and by multi-trait model (MT). 
As observed for phenotypic variances, the genetic variances obtained with the RRM were also closely similar and showed the same trend throughout lactation, except for the first week. At the beginning of the lactation period inflated genetic variances were observed for the AS.5.5.het6 and LEG.6.7.het6 when compared to the other models. Except for weeks 20 to 32 of lactation, the genetic variances obtained with the four RRM presented a magnitude similar to that of variances estimated by multi-trait analysis. As evidenced by Meyer (2005), RRM fitting B-splines were less susceptible to implausible genetic variance estimates at extremes of the trajectory.

With respect to environmental variances, corresponding to the sum of permanent and temporary environmental variances when estimated by random regression and only to residual variances when estimated by multi-trait analysis. The largest differences between models were observed at the beginning of lactation. Similar estimates were observed close to mid-lactation, whereas higher estimates were obtained by multi-trait analysis at the end of lactation (compensating for the difference in genetic variances since the phenotypic variances were similar). The highest permanent environmental variances (not shown) estimated with the RRM were observed at the beginning and at the end of lactation. The same trend for Holstein cattle has been reported by Melo et al. (2003), Cobuci et al. (2005) and Costa et al. (2008) and indicates that environmental factors exerted a marked influence during these periods.

Heritability estimates presented similar trend during mid-lactation (13 to 31 weeks) and between week 37 and the end of lactation, for all RRM (Figure 3). Heritabilities obtained by multi-trait analysis were of a lower magnitude than those estimated by RRM, explained by higher temporary environmental and lower additive genetic variances. The LEG.6.7.het6 model presented higher fluctuation for the heritabilities in the course of lactation, probably, as consequence of the higher polynomial order applied to adjust this effect. For the model using the B-spline function, the heritability estimates presented smaller oscillations throughout lactation. This finding is in agreement with Meyer (2005) who, studying the growth of beef cattle, found that B-spline functions are less susceptible to problems of erratic estimates at the ends of the curves, a problem frequently encountered with Legendre polynomials. This lower susceptibility is due to the fact that models using B-splines contain individual segments of low-degree polynomials and permit a better control of the overall influence of individual observations.

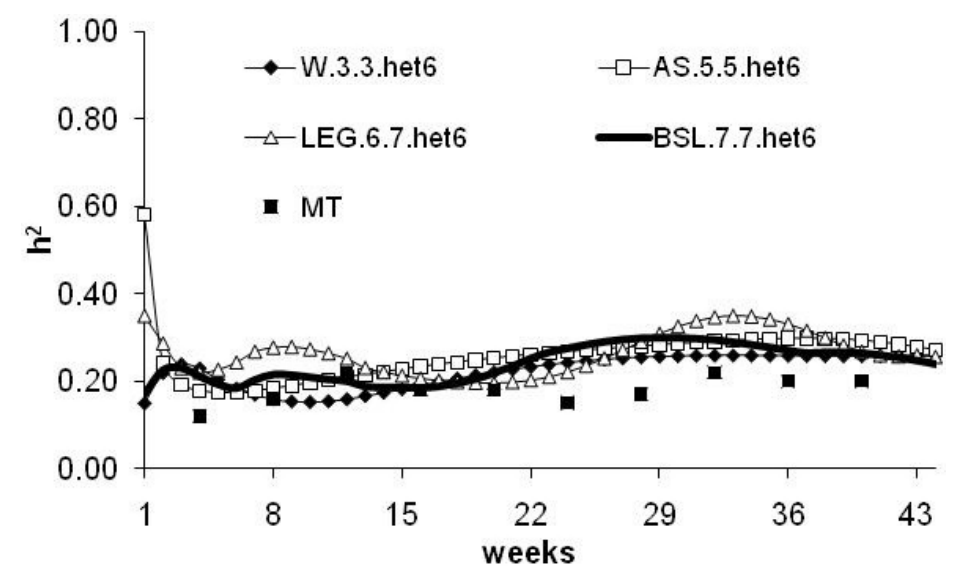

Figure 3. Heritability estimates for weekly test-day milk yield obtained W.3.3het6, AS.5.5.het6, LEG.6.7.het6, BSL.7.7.het6 the random regression models and by multi-trait model (MT). 
At the beginning of the lactation inflated heritabilities were observed for the AS.5.5.het6 when compared to the other RRM models (Figure 3). The heritabilities ranged from 0.15 to 0.26 for W.3.3het6, from 0.17 to 0.58 for AS.5.5.het6, from 0.17 to 0.30 for BSL.7.7.het6, from 0.20 to 0.35 for LEG.6.7.het6 and from 0.12 to 0.22 for the multi-trait model. MT model showed estimates heritabilities more flat, with lower estimative in the middle of lactation (week 24). At the beginning of lactation, the model AS.5.5.het6 overestimated the heritabilities. B-spline and Wilmink showed similar estimates. Several studies in Holstein cattle using RRM reported similar trend for TD heritability estimates as obtained in this study, Olori et al. (1999) and Kettunen et al. (2000), and in Brazil by Cobuci et al. (2005), Araújo et al. (2006), Melo et al. (2007) and Dorneles et al. (2009).

All RRM provided similar phenotypic correlations (not shown). Phenotypic correlations close to one were observed between adjacent test-day yields and these correlations decreased with increasing interval between test-days, irrespective of the function used. The phenotypic correlations were much lower than the genetic and permanent environmental correlations. Similar results have been reported by El Faro et al. (2008) for Caracu cattle.

As observed for phenotypic correlations, the genetic correlations were high for adjacent test-days and decreased with increasing distance between test-days (Figure 4). Fluctuations of these values during the lactation were greater before when the number of parameters was increased from 18 (W.3.3het6) to 62 (BSL.7.7.het6). Negative genetic correlations between initial and final test-days were obtained with the four models, irrespective of the function used. However, this frequency was very low for model BSL.7.7.het6. These negative genetic correlations can be attributed to the difficulty of modeling initial test-days milk yields of lactation, a phase during which the cow suffers from post-calving stress and also from an energy deficit. Negative genetic correlations estimated by RRM using different functions have also been reported for Holstein cattle by Jamrozik and Schaeffer (1997), Olori et al. (1999), Brotherstone et al. (2000) and Kettunen et al. (2000), and in Brazil by Cobuci et al. (2005), Costa et al. (2008) and Bignardi et al. (2009a,b).

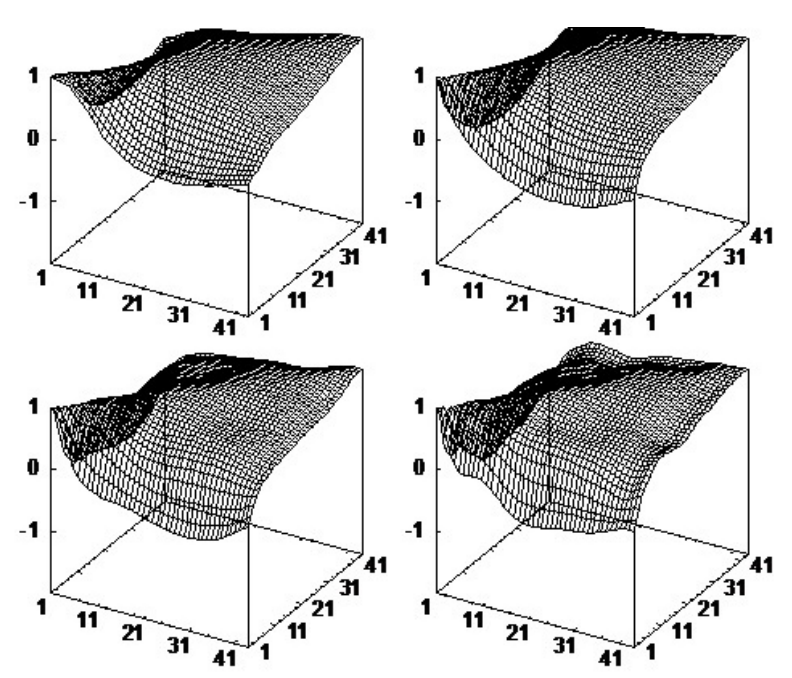

Figure 4. Genetic correlation estimates between weekly milk yields obtained with the W.3.3het6 ( $1^{\text {st }}$ row left), AS.5.5.het6 ( $1^{\text {st }}$ row right), LEG.6.7.het6 ( $2^{\text {nd }}$ row left $)$ e BSL.7.7.het6 ( $2^{\text {nd }}$ row right). 
The surfaces of the permanent environmental correlations differed between the four models (Figure 5). Such as phenotypic and genetic, the permanent environmental correlation estimates were higher for adjacent weeks. Although similar permanent environmental correlations were obtained with models LEG.6.7.het6 and BSL.7.7.het6, wider oscillations along lactation were observed for model LEG.6.7.het6.

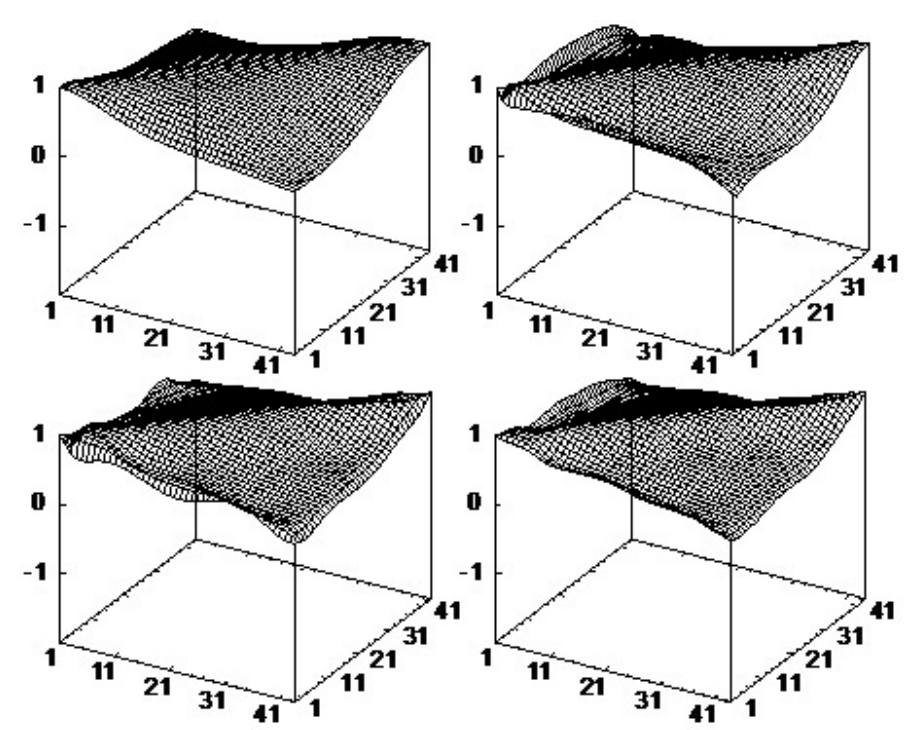

Figure 5. Permanent environmental correlation estimates between weekly milk yields obtained with the W.3.3het6 ( $1^{\text {st }}$ row left $)$, AS.5.5.het6 ( $1^{\text {st }}$ row right $)$, LEG.6.7.het6 ( $2^{\text {nd }}$ row left $)$ e BSL.7.7.het6 ( ${ }^{\text {nd }}$ row right $)$.

The difficulties to establish criteria for the choice of the best RRM are evident. In principle, AIC and BIC tests, were regarded to be sufficient as a criteria of choice, but, in fact, the estimates of genetic parameters also proved to be helpful. In general, the largest number of parameters in the additive genetic and permanent environmental function caused a greater flexibility of the RRM and the heritability and genetic correlation estimates were affected. In the present study, although the model using Legendre polynomials fits the data set better than others models according to the adopted criteria, there are several problems associated with it. The genetic variance follows more oscillatory patterns, and negative correlations for the extremes of lactation. A higher number of parameters were necessary to reach a similar fit as the obtained with model using Legendre (LEG.6.7.het6) when RRM on B-splines functions were applied (BSL.7.7.het6). On the other hand, although RRM that used B-spline functions were more parameterized than the Legendre models, they had faster convergence in the estimation of variance components, which is favorable when analyzing a large amount of data. In addition, B-spline functions were less susceptible to implausible genetic variance estimates at extremes of the trajectory.

In conclusion, random regression models with higher number of parameters were more useful to describe the genetic variation of test-day milk yield during the lactation period. Random regression models using B-spline and Legendre polynomials as base functions seems to be the most adequate to describe the covariance structure of the data. 


\title{
ACKNOWLEDGMENTS
}

\author{
Research supported by Fundação de Amparo à Pesquisa do Estado de São Paulo \\ (FAPESP) Brazil.
}

\section{REFERENCES}

Ali TE and Schaeffer LR (1987). Accounting for covariances among test day milk yields in dairy cows. J. Anim. Sci. 67: 637-644.

Araújo CV, Torres RA, Costa C, Torres Filho RA, et al. (2006). Uso de modelos de regressão aleatória para descrever a variação genética da produção de leite na raça Holandesa. Rev. Bras. Zootec. 3: 975-981.

Bignardi AB, El Faro L, Cardoso VL, Machado PF, et al. (2009a). Random regression models to estimate test-day milk yield genetic parameters Holstein cows in southeastern Brazil. Livest. Sci. 123: 1-7.

Bignardi AB, El Faro L, Cardoso VL, Machado PF, et al. (2009b). Parametric correlation functions to model the structure of permanent environmental (co)variances in milk yield random regression models. J. Dairy Sci. 92: 4634-4640.

Brotherstone S, White IMS and Meyer K (2000). Genetic modeling of daily yields using orthogonal polynomials and parametric curves. J. Anim. Sci. 70: 407-415.

Cobuci JA, Euclydes RF, Lopes PS, Costa CN, et al. (2005). Estimation of genetic parameters for test-day milk yield in Holstein cows using a random regression models. Genet. Mol. Biol. 28: 75-83.

Costa CN, Melo CNR, Pacher IU, Freitas AF, et al. (2008). Genetic parameters for test day milk yield of first lactation Holstein cows estimated by random regression using Legendre polynomials. Rev. Bras. Zootec. 37: 602-608.

Dorneles CKP, Cobuci JA, Rorato PRN, Weber T, et al. (2009). Estimação de parâmetros genéticos para produção de leite de vacas da raça Holandesa via regressão aleatória. Arq. Bras. Med. Vet. Zootec. 61: 407-412.

El Faro L and Albuquerque LG (2003). Utilização de modelos de regressão aleatória para produção de leite no dia do controle, com diferentes estruturas de variâncias residuais. Rev. Bras. Zootec. 32: 1104-1113.

El Faro L, Cardoso VL and Albuquerque LG (2008). Variance component estimates applying random regression models for test-day milk yield in Caracu heifers (Bos taurus Artiodactyla, Bovidae). Genet. Mol. Biol. 31: 665-673.

Fuller WA (1969). Grafted polynomials as approximating functions. Aust. J. Agr. Econ. 13: 35-46.

Jamrozik J and Schaeffer LR (1997). Estimates of genetic parameters for a test day model with random regressions for yield traits of first lactation Holsteins. J. Dairy Sci. 80: 762-770.

Jamrozik J, Kistemaker GJ, Dekkers JC and Schaeffer LR (1997). Comparison of possible covariates for use in a random regression model for analyses of test day yields. J. Dairy Sci. 80: 2550-2556.

Jensen J (2001). Genetic evaluation of dairy cattle using test-day models. J. Dairy Sci. 84: 2803-2812.

Kettunen A, Mäntysaari EA and Pösö J (2000). Estimation of genetic parameters for daily milk yield of primiparous Ayrshire cows by random regression test-day models. Livest. Prod. Sci. 66: 251-261.

Melo CMR, Packer IU, Costa CN and Machado PF (2007). Genetic parameters for test day milk yields of first lactation Holstein cows by random regression models. Animal 1: 325-334.

Meyer K (2005). Random regression analyses using B-splines to model growth of Australian Angus cattle. Genet. Sel. Evol. 37: 473-500.

Meyer K (2006). "WOMBAT" - Digging Deep for Quantitative Genetic Analyses by Restricted Maximum Likelihood. CD-ROM. Proceedings of the 8th World Congress of Genetic and Applied Livestock Production, Belo Horizonte.

Olori VE, Hill WG, Mcguirk BJ and Brotherstone S (1999). Estimating variance components for test day milk records by restricted maximum likelihood with a random regression animal model. Livest. Prod. Sci. 61: 53-63.

Rice JA and Wu CO (2001). Nonparametric mixed effects models for unequally sampled noisy curves. Biometrics 57: 253-259.

Ruppert D, Wand MP and Carroll RJ (2003). Semiparametric Regression. Cambridge University Press, New York.

Schenkel FS (1989). The Use of Segmented Polynomials on Animal Science Research (Theoretical and Practical Considerations). Universidade Federal do Rio Grande do Sul, Porto Alegre.

Strabel T and Misztal I (1999). Genetic parameters for first and second lactation milk yields of Polish black and white cattle with random regression test-day models. J. Dairy Sci. 82: 2805-2810.

Wilmink JBM (1987). Adjustment of test-day milk, fat and protein yield for age, season and stage of lactation. Livest. Prod. Sci. 16: 335-348.

Wolfinger RD (1993). Covariance structure selection in general mixed models. Commun. Stat.-Simul. Comput. 22: 1079-1106. 